Pierre Corvol François Alhenc-Gelas Florent Soubrier

\title{
L'endothélium, site de production et de métabolisme des peptides vasoactifs
}

Parmi les nombreuses fonctions qu'assure l'endothélium vasculaire, celle de production et de métabolisme des produits vaso-actifs est essentielle pour le contrôle du tonus vasculaire et de la structure de la paroi artérielle. Trois ecto-enzymes faisant partie de la famille des métalloprotéines à zinc y concourent : l'enzyme de conversion de l'angiotensine I (ECA) qui active l'angiotensine I en angiotensine II, et qui inactive la bradykinine ; l'endopeptidase neutre (NEP), qui inactive le facteur natriurétique auriculaire; l'enzyme de conversion de l'endothéline (ECE) qui convertit la big endothéline, précurseur inactif de l'endothéline, en endothéline. La paroi vasculaire est apparemment aussi capable de capter et de concentrer les éléments du système rénineangiotensine circulant, voire de les synthétiser. L'endothélium synthétise la bradykinine et l'endothéline I qui ont un effet paracrine sur la cellule musculaire lisse vasculaire. Ainsi la cellule endothéliale joue-t-elle un double rôle en contrôlant par l'intermédiaire de ces peptides le débit sanguin tissulaire local et la structure de la paroi artérielle sous-jacente. Du fait de sa position privilégiée entre sang et vaisseaux, l'endothélium est une cible intéressante pour les médicaments interférant avec la synthèse ou l'action des peptides vasoactifs.

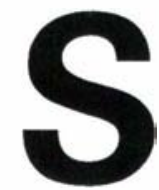

itué à l'interface du sang et des tissus, l'endothélium vasculaire capte et décode les différents messages sanguins, hémodynamiques, chimiques et biochimiques, les transforme et les transmet à la paroi vasculaire où il exerce des effets à court et à long terme. A court terme, l'endothélium module le tonus vasculaire par la production de subs- tances vasorelaxantes (prostacycline, monoxyde d'azote et, peut-être, bradykinine) et vasocontracturantes (endothéline, angiotensine II). A long terme, il influence la structure de la paroi artérielle en produisant ces mêmes facteurs qui peuvent stimuler (endothéline, angiotensine II) ou inhiber (monoxyde d'azote) la croissance des cellules musculaires lisses vasculaires. Ainsi, la cellule endothéliale
F. Soubrier : directeur de recherche Cnrs, Inserm, U. 36, 3, rue d'Ulm, 75005 Paris, France. 
joue-t-elle un double rôle en contrôlant à la fois l'état de tension du vaisseau, donc le débit sanguin tissulaire, et la structure de la paroi artérielle. La cellule endothéliale est un passage obligé pour le transfert des peptides du compartiment sanguin aux cellules musculaires lisses vasculaires, pour la production et le métabolisme des peptides vasoactifs. Le flux sanguin délivré aux tissus est réglé à la fois au niveau général de l'organisme et au niveau local, tissulaire. Le système rénine-angiotensine circulant correspond au premier type de régulation : un message hémodynamique systémique perçu par le rein provoque une variation des taux de rénine et d'angiotensine circulantes. L'endothélium intervient dans cette régulation en assurant la conversion de l'angio- tensine I en angiotensine II et son transport vers les cellules musculaires lisses vasculaires. La modulation locale des flux tissulaires fait intervenir la synthèse in situ de peptides vasoactifs par l'endothélium, tels que l'endothéline 1 et peut-être la bradykinine. La terminaison de l'action des peptides vasoactifs est aussi, en partie, assurée par l'endothélium : bradykine, endothéline et peptide natriurétique auriculaire (ANP) sont dégradés par les cellules endothéliales. Trois enzymes endothéliales jouent un rôle important dans le métabolisme des peptides vasoactifs : l'enzyme de conversion de l'angiotensine I (ECA), l'endopeptidase neutre (NEP) et l'enzyme de conversion de la big endothéline (ECE). Ces trois enzymes appartiennent, pour les deux premières et probablement pour la troisième, à la classe des métallopeptidases à zinc. Cette revue s'attachera aux propriétés principales de ces enzymes et fera brièvement le point sur la synthèse et la production locale de l'angiotensine II, de la bradykinine et de l'endothéline 1 .

\section{Activation et inactivation des peptides vasoactifs dans I'endothélium}

\section{Enzyme de conversion de l'angio- tensine (ECA)}

L'ECA (dipeptidyl carboxypeptidase I ; EC 3.4.15.1) est l'archétype des ectoenzymes de la cellule endothéliale, impliquées dans l'activation et

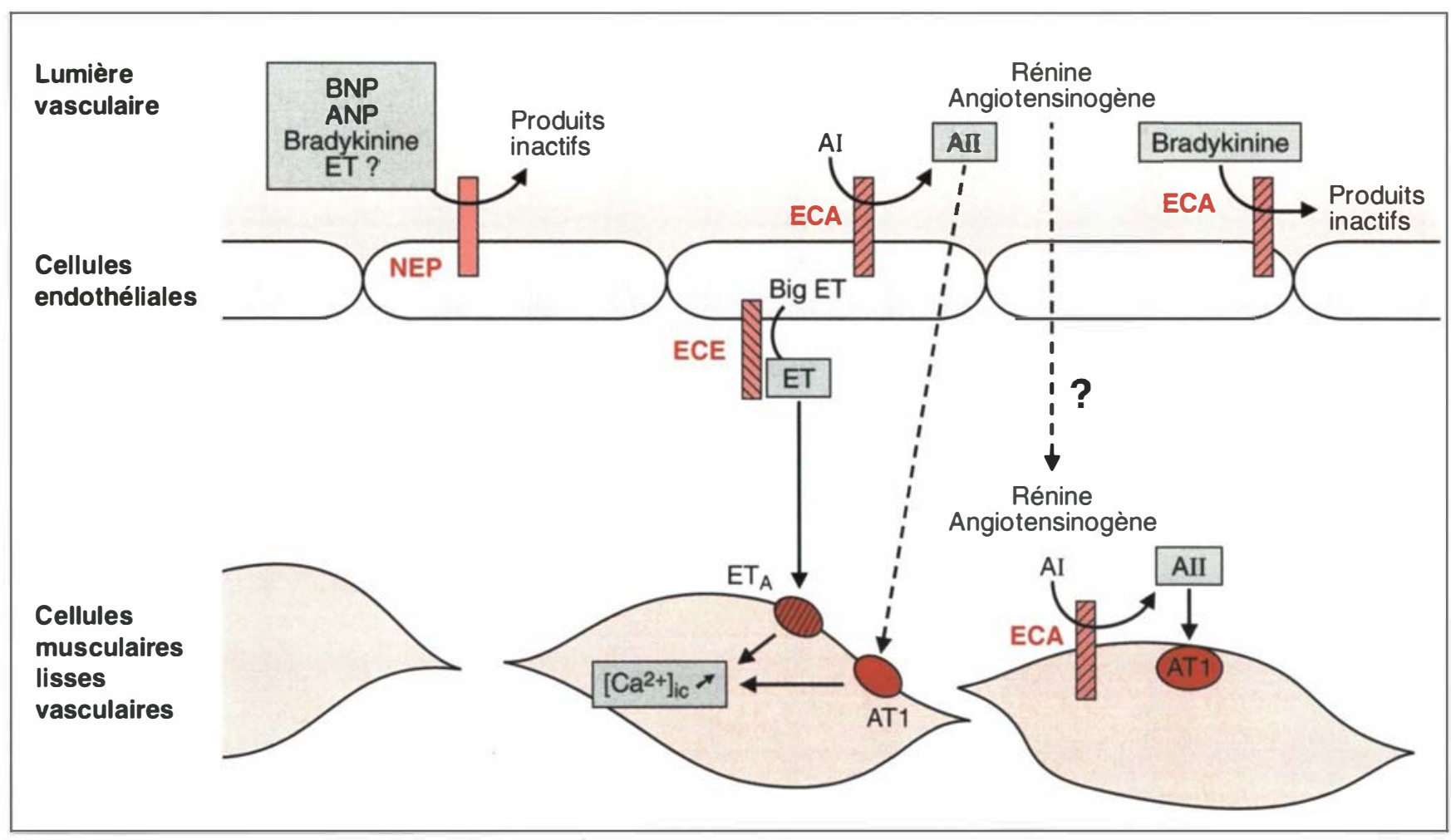

Figure 1. Production de peptides vaso-actifs dans la paroi vasculaire. La cellule endothéliale synthétise la big endothéline (BigET), précurseur inactif de l'endothéline (ET). La big endothéline est convertie en endothéline par une enzyme de conversion (ECE), peut-être située préférentiellement du côté abluminal de la cellule endothéliale. Elle se lie au récepteur $E T_{A}$ des cellules musculaires lisses vasculaires sous-jacentes. L'endopeptidase neutre (NEP) hydrolyse des peptides vaso-actifs : brain natriuretic peptide (BNP), peptide natriurétique auriculaire (ANP), bradykinine et, peutêtre, endothéline. L'enzyme de conversion de l'angiotensine I (ECA) convertit l'angiotensine I (AI) en angiotensine II (AII) qui se lie au récepteur des cellules musculaires lisses vasculaires (AT1). La stimulation des récepteurs ET et AT1 conduit à une élévation du calcium intracellulaire et à une vasoconstriction. La rénine et l'angiotensinogène plasmatique pourraient être en partie séquestrées dans la paroi artérielle et engendrer localement de l'angiotensine I. Celle-ci serait convertie en angiotensine II par I'ECA présente dans les cellules musculaires lisses vasculaires. 
l'inactivation des peptides vasoactifs.

1. Ng KKF, Vane JR. Conversion of angiotensin I to angiotensin II. Nature 1967 ; $216: 762-6$.

2. Caldwell PR, Seegal BC, Hsu KC, Das $M$, Soffer RL. Angiotensin-converting enzyme : vascular endothelial localization. Science 1976 ; 191 : 1050-1.

3. $\mathrm{Ng} \mathrm{KKF}$, Vane JR. Fate of angiotensin I in the circulation. Nature 1968; 218 : 144-50.

4. Soubrier F, Alhenc-Gelas F, Hubert C, Allegrini J, John M, Tregear G, Corvol P. Two putative active centers in human angiotensin I-converting enzyme revealed by molecular cloning. Proc Natl Acad Sci USA $1988 ; 85: 9386-90$.

5. Hubert C, Houot A-M, Corvol P, Soubrier F. Structure of the angiotensin Iconverting enzyme gene. Two alternate promoters correspond to evolutionary steps of a duplicated gene. J Biol Chem 1991; 266 : 15377-83.

6. Cornell M-J, Coates D, Isaac RE. Characterization of putative drosophila angiotensin converting enzyme cDNA clones. Biochem Soc Transactions (abst.) $1993 ; 21: 243 \mathrm{~S}$.

7. Wei L, Alhenc-Gelas F, Corvol P, Clauser $\mathrm{E}$. The two homologous domains of the human angiotensin I-converting enzyme are both catalytically active. J Biol Chem 1991 ; 266 : 9002-8.

8. Ehlers MRW, Riordan JF. Angiotensinconverting enzyme : Zinc- and inhibitor binding stoichiometries of the somatic and testis isozymes. Biochemistry 1991; 30 : 7118-26.

9. Wei L, Clauser E, Alhenc-Gelas F, Corvol $P$. The two homologous domains of human angiotensin I-converting enzyme interact differently with competitive inhibitors. J Biol Chem 1992 ; 267 : 13398-405.

10. Jaspar E, Wei L, Alhenc-Gelas F. Differences in the properties and enzymatic specificities of the two active sites of angiotensin I-converting enzyme (Kininase II) : studies with bradykinine and other natural peptides. J Biol Chem 1993; 268 : 9496-503.

11. Wei L, Alhenc-Gelas F, Soubrier F, Michaud A, Corvol P, Clauser E. Expression and characterization of recombinant human angiotensin I-converting enzyme. Evidence for a C-terminal transmembrane anchor and for a proteolytic processing of the secreted recombinant and plasma enzymes. J Biol Chem 1991; 266 : 5540-6.

12. Hooper NM, Keen J, Pappin DJC, Turner AJ. Pig kidney angiotensinconverting enzyme. Purification and characterization of amphiphatic and hydrophilic forms of the enzyme establishes C-terminal anchorage to the plasma membrane. Biochem
13. Oppong SY, Hooper NM. Characterization of a secretase activity which releases angiotensin-converting enzyme from the membrane. Biochem J 1993 ; 292 : 597-603.

14. Linz W, Schölkens BA, Ganten D. Converting enzyme inhibition specifically prevents the development and induces the regression of cardiac hypertrophy in rats. Clin Exp Hypertens 1989; $11: 1325-50$.

15. Cambien F, Alhenc-Gelas F, Herbeth B, Andre JL, Rakotovao R, Gonzales MF, Allegrini J, Bloch C. Familial resemblance of plasma angiotensin-converting enzyme level : the Nancy study. Am J Hum Genet $1988 ; 43$ : 774-80.

16. Mendelsohn FAO, Lloyd CJ, Kachel C, Funder JW. Induction by glucocorticoids of angiotensin-converting enzyme production from bovine endothelial cells in culture and rat lung in vivo. J Clin Invest $1982 ; 70$ : 684-92.

17. Krulewitz AH, Baur WE, Fanburg BL Hormonal influence on endothelial cell angiotensin-converting enzyme activity. $\mathrm{Am}$ $J$ Physiol 1984 ; 247 : C163-8.

18. Shai S-Y, Fishel RS, Martin BM, Berk $\mathrm{BC}$, Bernstcin KB. Bovine angiotensin converting enzyme cDNA cloning and regulation. Increased expression during endothelial cell growth arrest. Circ Res $1992 ; 70$ : 1274-81.

19. Shunkert H, Dzau VJ, Tang SS, Hirsch AT, Apstein CS, Lorell BH. Increased rat cardiac angiotensin converting enzyme activity and mRNA expression in pressure overload ventricular hypertrophy : cffects on coronary resistance, contractility and relaxation. J Clin Invest $1990 ; 86$ : 1913-20.

20. Hisch AT, Talsness CE, Schunkert $H$, Paul M, Dzau VJ. Tissue specific activation of cardiac angiotensin converting cnzyme in experimental heart failure. Circ Res 1991; 69: 475-82.

21. Fabris B, Jackson B, Kohzuki M, Perich R, Johnston CI. Increased cardiac angiotensin-converting enzyme in rats with chronic heart failure. Clin Exp Pharmacol Physiol 1990 ; 17 : 309-14.

22. Shiota N, Miyazaki M, Okunushi M Increase of angiotensin converting enzyme gene expression in the hypertensive aorta. Hypertension 1992 ; 20 : 168-74.

23. King SJ, Oparil S. Converting-enzyme inhibitors increase converting enzyme mRNA and activity in endothelial cells. $A m$ J Physiol 1992 ; 263 : C743-9.

24. Rigat B, Hubert C, Alhenc-Gelas F, Cambien F, Corvol P, Soubrier F. An insertion/deletion polymorphism in the angiotensin I-converting enzyme gene accounting for half the variance of serum enzyme levels. J Clin Invest $1990 ; 86$ : 1343-6.
L'ECA agit essentiellement comme une dipeptidyl carboxypeptidase. Elle active l'angiotensine I en angiotensine II par clivage du dipeptide carboxyterminal His-Leu de l'angiotensine I et inactive la bradykinine par hydrolyse séquentielle de deux dipeptides carboxy-terminaux. La conversion de l'angiotensine I en angiotensine II et l'inactivation de la bradykinine s'effectuent essentiellement dans le poumon, riche en cellules endothéliales capillaires [1-3] mais probablement aussi dans d'autres lits artériels ou capillaires. L'ECA circulante ne joue qu'un rôle modeste dans cette conversion.

Le clonage moléculaire de l'ADNc de l'ECA endothéliale humaine a montré que l'enzyme présente deux domaines hautement homologues, $\mathrm{N}$ et C-terminaux [4]. L'homologie de séquence atteint $90 \%$ dans la région comprenant les acides aminés du site catalytique. Cette structure de la protéine suggérait l'existence d'une duplication génique au cours de l'évolution, hypothèse confirmée par l'élucidation de l'organisation du gène [5]. La découverte que l'ECA de la drosophile ne comporte qu'un seul domaine fonctionnel, relativement similaire au domaine Cterminal de l'ECA somatique humain, donne une première indication sur la date de duplication [6]. Chaque domaine comprend une séquence conservée qui est un motif commun aux métalloprotéases à zinc (His-Glu-Xaa-Xaa-His). L'atome de zinc du site actif est coordiné par les deux histidines et un troisième ligand situé à distance dans la séquence. L'attaque nucléophilique de la liaison peptidique s'effectue, grâce au glutamate, par la molécule d'eau polarisée par le zinc. La découverte de deux sites catalytiques putatifs dans l'ECA était inattendue car les études antérieures avaient suggéré la présence d'un seul atome de zinc et la liaison d'une seule molécule d'inhibiteur par molécule d'enzyme. Des expériences de mutagenèse dirigée sur les sites catalytiques des domaines $\mathrm{N}$ et C-terminaux ont montré que les deux sites catalytiques de l'ECA étaient fonctionnels et indépendants [7]. De nouvelles études ont montré qu'une mole d'ECA contient bien 


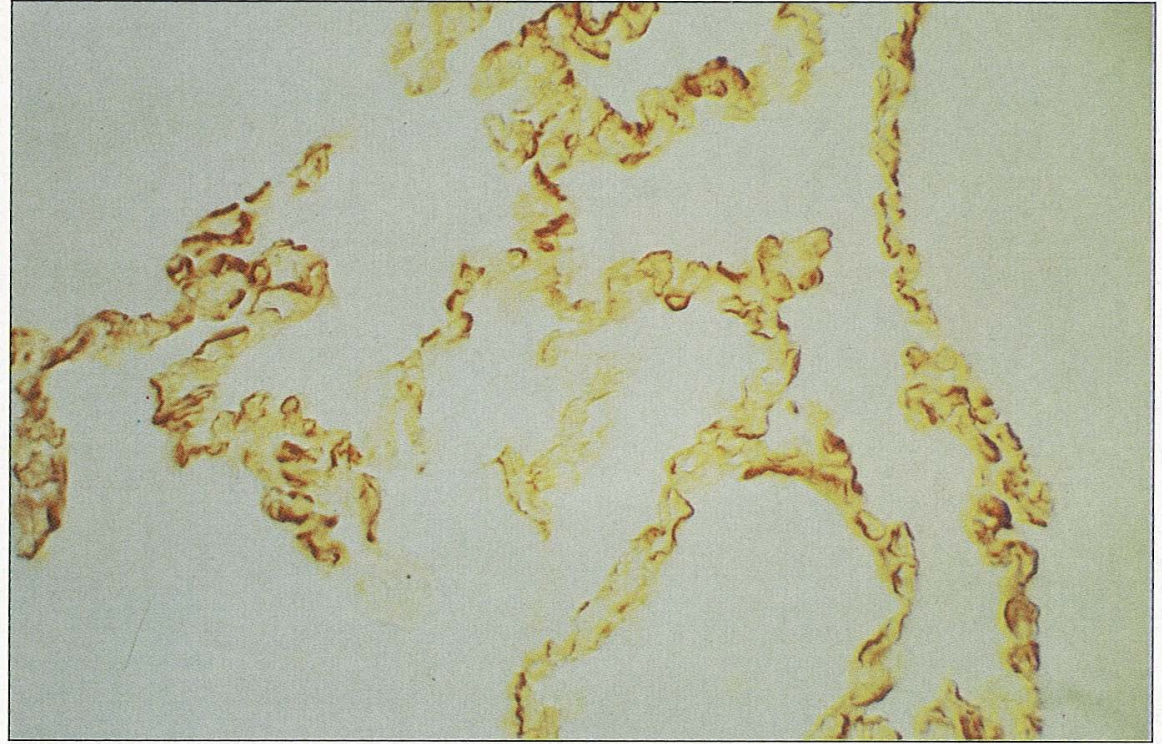

Figure 2. Immunocoloration de l'enzyme de conversion de l'angiotensine I à la surface de l'endothélium pulmonaire. L'enzyme, présente seulement à la surface des cellules endothéliales, est révélée par le précipité brun foncé de la diaminobenzidine. Les autres composants du parenchyme pulmonaire, colorés en brun clair, n'expriment pas l'enzyme. Coupe de poumon de ouistiti. X500. (Cliché J.-M. Gasc, Inserm U. 36.)

deux atomes de zinc [8] et peut lier deux molécules d'inhibiteurs radioactifs $[8,9]$.

La découverte de deux sites actifs dans l'ECA soulève la question intéressante d'une éventuelle bifonctionnalité de l'enzyme. Toutefois, les deux substrats physiologiques de l'enzyme endothéliale, l'angiotensine I et la bradykinine, sont hydrolysés de façon quasi similaire par les deux sites catalytiques, le domaine Cterminal hydrolysant cependant un peu plus rapidement l'angiotensine I que le domaine $\mathrm{N}$-terminal [10].

Une séquence de 17 acides aminés hydrophobes, constituant une hélice $\alpha$, se trouve à l'extrémité C-terminale de l'enzyme. Elle est responsable de l'ancrage de l'ECA dans la membrane plasmique, comme le montrent des expériences de mutagenèse dirigée : l'introduction par mutagenèse dirigée d'un codon stop juste en amont de la séquence hydrophobe d'ancrage membranaire conduit à une enzyme sécrétée dans le milieu de culture des cellules $\mathrm{CHO}$ transfectées [11]. Les deux domaines de l'ECA se trouvent donc exposés à la surface externe de la cellule et hydrolysent les substrats circulants ou $m / s n^{\circ} 10$ vol. 9, octobre 93 laire, les cellules musculaires lisses vasculaires et l'adventice. Elle pourrait y engendrer l'angiotensine II à partir de l'angiotensine I, elle-même produite localement du fait de la présence de la rénine et de l'angiotensinogène dans la paroi vasculaire (voir plus bas). L'existence d'ECA dans la paroi des vaisseaux qui irriguent le cœur, le rein et le cerveau mérite d'être soulignée. L'angiotensine I pourrait y être activée par l'ECA locale, sans participation de l'ECA plasmatique. Il est concevable que la concentration d'ECA tissulaire soit critique pour la production d'angiotensine II dont les effets sont particulièrement importants aux niveaux cardiaque, rénal et cérébral. Les inhibiteurs de l'enzyme de conversion inhibent l'enzyme plasmatique et tissulaire. Une question importante et non résolue est de savoir la part relative de l'inhibition plasmatique ou tissulaire de l'ECA dans les effets de ces médicaments. Il est possible que les effets antihypertrophiques des inhibiteurs de l'enzyme de conversion sur les cellules musculaires lisses vasculaires ou sur les cellules myocardiques dépendent plus de l'inhibition de l'enzyme tissulaire que de l'enzyme plasmatique [14].

Étant donné le rôle limitant que pourrait avoir l'ECA dans la production locale de l'angiotensine II, il est intéressant de constater que cette enzyme est soumise à une régulation physiologique, pharmacologique et pathologique et à des variations d'origine génétique. Le taux d'ECA plasmatique s'abaisse progressivement lors de la puberté, restant équivalent dans les deux sexes [15]. La thyroïdectomie entraîne une diminution des concentrations d'ECA plasmatique. Les hormones thyroïdiennes et les glucocorticoïdes augmentent, par ailleurs, la production d'ECA dans les cultures de cellules endothéliales [16, 17]. Enfin, la concentration d'ECA et l'expression du gène de l'ECA sont accrus lors de l'arrêt de croissance des cellules endothéliales en culture, ce qui pourrait avoir une conséquence importante sur le métabolisme des peptides vaso-actifs lors de la régénération des cellules endothéliales après lésion vasculaire [18].

L'ECA tissulaire, notamment cardiaque et vasculaire, varie aussi lors de
L'ECA est aussi présente dans les autres constituants de la paroi vascu- 


\section{RÉFÉRENCES}

25. Tiret L, Rigat B, Visvikis S, Breda C, Corvol P, Cambien F, Soubrier F. Evidence, from combined segregation and linkage analysis, that a variant of the angiotensin I-converting enzyme (ECA) gene controls plasma ECA levels. Am J Hum Genet 1992 ; $51: 197-205$

26. Costerousse O, Allegrini J, Lopez M, Alhenc-Gelas F. Angiotensin I-converting enzyme in human circulatory mononuclear cells. Genetic polymorphism in $\mathrm{T}$ lymphocytes. Biochem J 1993 ; 290 : 33-40.

27. Jeunemaitre $X$, Lifton RP, Hunt SC, Williams RR, Lalouel JM. Absence of linkage between the angiotensin-converting enzyme and human essential hypertension. Nature Genet 1992 ; 1 : 72-5.

28. Cambien F, Poirier O, Lecerf L, et al. Polymorphism in the gene for angiotensinconverting enzyme is a potent risk factor for myocardial infarction. Nature $1992 ; 259$ 641-4.

29. Pfeffer MA, Braunwald E, Moge LA, et al. Effect of captopril on mortality and morbidity in patients with left ventricular dysfunction after myocardial infarction. N England J Med 1992 ; 327 : 669-77.

30. The SOLVD Investigators. Effect of enalapril on mortality and the development of heart failure in asymptomatic patients with reduced left ventricular ejection fractions. N England J Med $1992 ; 327$ : 685-91.

31. Roques BP, Noble F, Dangi F, Fournié-Zaluski M-C, Beaumont A. Neutral endopeptidase 24.11 : structure, inhibition and experimental and clinical pharmacology. Pharmacol Rev 1993 ; 45 : 87-146.

32. Soleilhac JM, Lucas E, Beaumont A, Turcaud S, Michel JB, Ficheux D, FourniéZaluski M-C, Roques BP. A 94 kDa protein, identified as neutral endopeptidase-24.11, can inactivate atrial natriuretic peptide in the vascular endothelium. Mol Pharmacol 1992 ; 41 : 609-14.

33. Dutriez I, Salis N, Fournié-Zailuski M-C, Roques BP. Pre- and post-natal ontogeny of neutral endopeptidase 24-11 (" enkephalinase ") studied by in vitro autoradiography in the rat. Experientia 1992; 48 : 290-300.

34. Llorens-Cortes C, Huang $\mathrm{H}$, Vicart $\mathrm{P}$, Gasc J-M, Paulin D, Corvol P. Identification and characterization of neutral endopeptidase in endothelial cells from venous or arterial origins. J Biol Chem $1992 ; 267$ : 14012-8.

35. Sybertz EJ, Chiu PJS, Vemulapalli S, Pitts BJR, Watkins R, Foster CJ, Barnett A, Haslanger MF. SCH 39370, a neutral metalloendopeptidase inhibitor, potentiates biological responses to atrial natriuretic factor and lowers blood pressure in desoxycorticosterone acetate-sodium hypertension rats. $J$ Pharmacol Exp Ther 1989; $250: 624-31$.
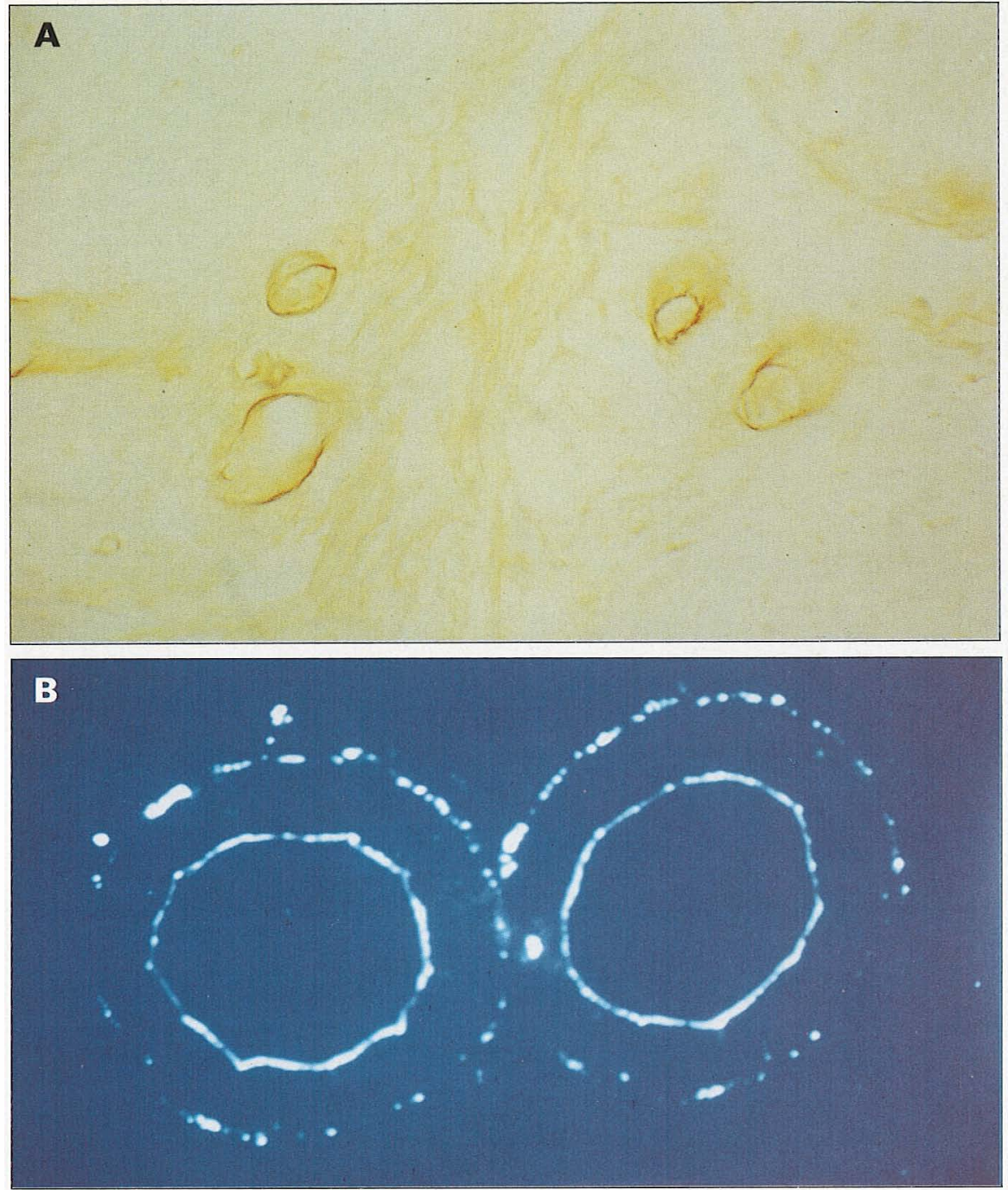

Figure 3. (A) Immunocoloration des vaisseaux sanguins par un anticorps dirigé contre l'enzyme de conversion de l'angiotensine I. La paroi interne des vaisseaux, tapissée de cellules endothéliales, est colorée en brun foncé par un précipité de diaminobenzidine qui révèle la présence de l'enzyme à leur surface. Coupe d'épididyme de ouistiti. X500. (Cliché J.-M. Gasc, Inserm U. 36.) (B) Localisation par autoradiographie de l'enzyme de conversion de I'angiotensine I dans I'aorte de chien. La paroi artérielle lendothélium et adventice) est marquée par l'inhibiteur de l'enzyme de conversion 351A iodé, dérivé du lisinopril. (Cliché aimablement fourni par F. Mendelsohn, Austin Hospital, Heildelberg, Australie.) 
certaines maladies : au cours de l'insuffisance cardiaque, le taux cardiaque d'ECA et celui de son ARNm s'élèvent $[19,20]$. L'infarctus du myocarde expérimental entraîne une réaction inflammatoire et une cicatrice fibreuse myocardique où l'ECA est exprimée en grande quantité [21]. Ces productions locales d'ECA pourraient avoir des conséquences physiopathologiques importantes du fait de l'effet inotrope positif de l'angiotensine II et anti-arythmogène de la bradykinine et du fait des actions opposées de ces médiateurs sur la croissance cellulaire. L'hypertension artérielle expérimentale chez le rat s'accompagne, elle aussi, d'une augmentation du taux d'ECA et de son ARNm dans la paroi artérielle (aorte, vaisseaux rénaux): l'hypertension rénovasculaire accroît le taux d'ECA vasculaire, peut-être par surexpression de l'enzyme dans les cellules musculaires lisses vasculaires [22]. Enfin, le traitement par les inhibiteurs de l'enzyme de conversion augmente nettement l'expression de l'ECA circulante et tissulaire. Récemment, King et Oparil ont montré que l'addition d'inhibiteurs de l'enzyme de conversion à des cellules endothéliales en culture augmentait le taux de transcription du gène de l'ECA [23]. L'effecteur de cette régulation n'est pas connu. L'ECA ne s'élève pas lors d'un traitement par d'autres inhibiteurs du système rénine-angiotensine, tels que les inhi- biteurs de la rénine ou les antagonistes non peptidiques de l'angiotensine II, excluant a priori l'implication de l'angiotensine II dans cette régulation.

La constatation la plus intéressante est le déterminisme génétique du taux de l'enzyme de conversion plasmatique. Les études faites chez l'homme ont montré une ressemblance familiale de ce taux due à l'effet d'un gène majeur codominant [15]. Un polymorphisme à type d'insertion (I) ou de délétion (D) de 250 paires de bases dans l'intron $16 \mathrm{du}$ gène de l'ECA permet de classer les individus suivant leur génotype D ou I [24]. La fréquence de l'allèle I est de 0,44 et celle de l'allèle $\mathrm{D}$ de 0,56 . En utilisant ce polymorphisme comme marqueur génétique, on trouve une forte association entre le génotype de l'ECA et le taux plasmatique de l'enzyme. Des différentes études menées jusqu'à ce jour, il ressort que ce polymorphisme du gène de l'ECA est un marqueur neutre en étroit déséquilibre de liaison avec le variant putatif [25]. Ce marqueur rend compte d'environ $20 \%$ à $40 \%$ de la variance totale de l'ECA plasmatique. Le taux d'ECA dans les lymphocytes $T$ circulants est aussi génétiquement déterminé, les sujets porteurs du génotype DD ayant environ deux fois plus d'ECA cellulaire que les sujets II [26]. L'ensemble de ces études suggère que le niveau d'expression de l'ECA tissulaire est généti- quement déterminé et se reflète au niveau plasmatique.

Plusieurs études récentes ont recherché une liaison ou une association possible entre le polymorphisme du gène de l'ECA et différentes maladies cardiovasculaires. Une étude de liaison utilisant des paires de germains atteints d'hypertension artérielle et plusieurs études d'association n'ont pas montré de lien entre le niveau de la pression artérielle (ou l'hypertension artérielle) et le polymorphisme du gène de l'ECA [27]. En revanche, une étude cas-témoins, réalisée à Lille, Toulouse, Strasbourg et Belfast, a montré une sur-représentation du génotype DD chez les patients ayant eu un infarctus du myocarde par rapport aux patients témoins [28]. Le risque relatif de développer un infarctus du myocarde serait étroitement lié au génotype de l'ECA. Cela est particulièrement net chez les patients ne présentant pas les facteurs de risque cardiovasculaire habituels (surpoids, anomalies lipidiques). Cette observation, qui doit être confirmée par d'autres études, suggère que le déterminisme génétique du taux d'ECA constitue un facteur de risque pour le développement d'un infarctus du myocarde. Ces résultats peuvent être rapprochés de l'effet bénéfique des inhibiteurs de l'enzyme de conversion dans le postinfarctus où ils améliorent la survie des patients ayant une dysfonction ventriculaire gauche secondaire à un infarctus du myocarde [29, 30].

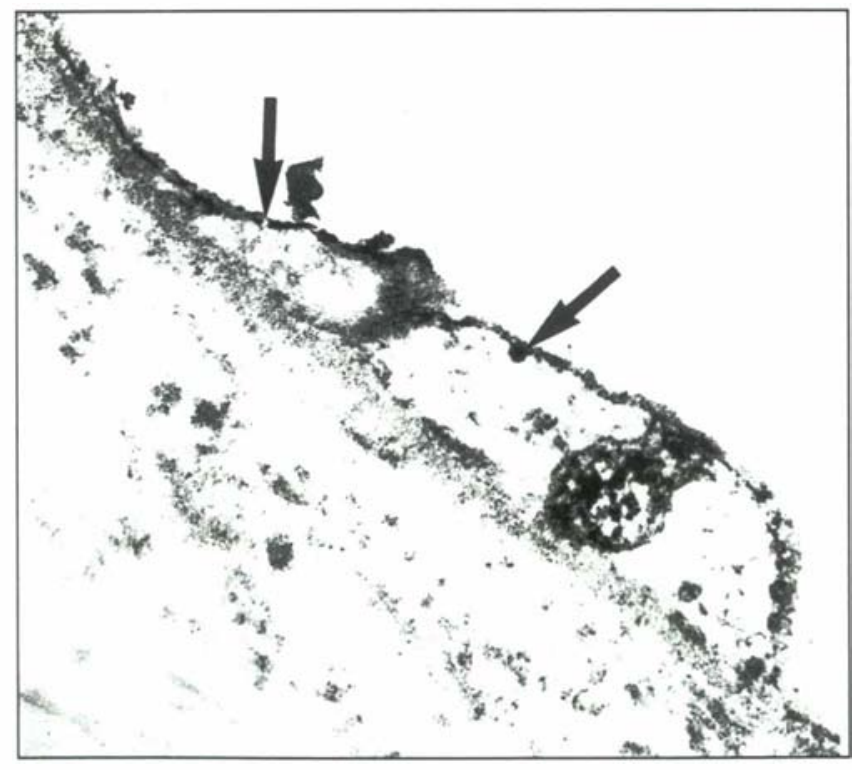

Figure 4. Immunohistochimie ultrastructurale de I'enzyme de conversion de l'angiotensine I (ECA). L'ECA est localisée sur le versant luminal des cellules endothéliales d'un capillaire interstitiel rénal humain (flèches). Le versant opposé de la cellule endothéliale ne présente pas d'ECA. Anticorps polyclonal antiECA rénal humain; technique peroxydase-antiperoxydase. $X 400000$. (Cliché aimablement fourni par P. Bruneval, laboratoire d'anatomie pathologie, hôpital Broussais, Paris, France.) 


\section{RÉFÉRENCES}

36. Gros C, Nocl N, Souque A, Schwartz JC, Danvy D, Plaquement JC, Duhamel L, Duhamel P, Lecomte JM, Bralet J. Mixed inhibitors of angiotensin converting enzyme and enkephalinase : rational design, properties and potential cardiovascular applications of glycopril and alatriopril. Proc Natl Acad Sci USA 1991; 88 : 4210-4.

37. Pham I, Gonzalez W, El Amrani AIK, Fournié-Zaluski MC, Philippc M, Laboulandine I, Roques BP, Michel JB. Effect of converting enzyme inhibitor and neutral endopeptidase inhibitor on renal function in experimental hypertension. J Pharmacol Exp Ther $1993 ; 265: 847-57$.

38. Yanasigawa $\mathbf{M}$, Kurihara $\mathrm{H}$, Kimura, et al. A novel potent vasoconstrictor peptide produced by vascular endothelial cells. Nature $1988 ; 332$ : 411-5.

39. Ohnaka $K$, Takayanagi $R$, Ymauchi $T$, Okazaki $H$, Ohashi $M$, Umeda $F$, Nawata $\mathrm{H}$. Identification and characterization of endothelin converting activity in cultured bovine endothelial cells. Biochem Biophys Res Commun 1990 ; 168 : 1128-36.

40. Okada K, Miyazaki Y, Takada J, Matsuyama $K$, Yamaki T, Yano $M$. Conversion of big endothelin-1 by membranebound metalloendopeptidase in cultured bovine endothelial cells. Biochem Biophys Res Commun 1990 ; 17 : 1192-8.

41. McMahon EG, Palomo MA, Moore WM, Stern MK. Phosphoramidon blocks the pressor activity of porcine big endothelin-1-(1-39) in vivo and conversion of big endothelin-1-(1-39) to endothelin-1-(1-21) in vitro. Proc Natl Acad Sci USA 1991; 88 . 703-7.

42. Sawamura T, Kasuya Y, Matsuhita Y, et al. Phosphoramidon inhibits the intracellular conversion of big endothelin-1 to endothelin-1 in cultured endothelial cells. Biochem Biophys Res Commun 1991; 174 779-84

43. Dzau VJ. Multiple pathways of angiotensin production in the blood vessel wall evidence, possibilitics and hypothesis. $J$ Hypertension 1989 ; 7 : 933-6.

44. Kifor I, Dzau VJ. Endothelial reninangiotensin pathway : evidence for intracellular synthesis and secretion of angiotensins. Circ Res 1987 ; 60 : 422-8.

45. Teutsch B, Bihoreau C, Monnot C, Bernstein K, Murphy TJ, Alexander WR, Corvol P, Clauser E. A recombinant rat vascular AT1 receptor confers growth propertics to angiotensin II in Chinese hamster ovary cells. Biochem Biophys Res Commun $1992 ; 187$ : 1381-8.

46. Gesterfer AAT, Peach MJ, Owens GK. Angiotensin II induces hypertrophy, not hyperplasia, of cultured rat aortic smooth muscle. Circ Res 1988 ; 62 : 749-56.

\section{Endopeptidase neutre (NEP)}

L'endopeptidase neutre (NEP), appelée aussi enképhalinase ( $\mathrm{EC}$ 3.4.24.11), est, comme l'ECA, une métalloprotéase membranaire à zinc qui agit sur de nombreux substrats [31]. Elle est localisée principalement dans le cerveau et dans les cellules épithéliales de différents organes, notamment le rein. La présence de NEP dans la paroi vasculaire et les cellules endothéliales a été récemment démontrée. Les préparations d'aortes de rat et de lapin clivent des substrats de la NEP, tels que l'enképhaline et le peptide natriurétique auriculaire ; les inhibiteurs spécifiques de la NEP bloquent cette activité enzymatique [32]. La présence de NEP dans la paroi artérielle au cours du développement du fotus de rat peut être mise en évidence par autoradiographie grâce à la liaison d'un inhibiteur spécifique tritié (figure 5) [33]. Llorens-Cortes et al. ont précisé que la NEP se trouvait dans les cellules endothéliales vasculaires, d'origine veineuse ou artérielle (figure 6): ces cellules contiennent l'ARNm de la NEP et l'enzyme hydrolyse un substrat naturel, la bradykinine [34]. Cette activité enzymatique est inhibée par le thiorphan, inhibiteur spécifique de la NEP.

La NEP des cellules endothéliales vasculaires pourrait joucr un rôle important en modifiant la concentration de certaines substances vasoactives circulantes ou produites localement. La NEP hydrolyse le peptide natriurétique auriculaire et le BNP (brain natriuretic peptide) qui agissent au niveau des cellules endothéliales via leur récepteur. La dégradation de ces peptides par la NEP vasculaire, conjointement à celle due à la NEP rénale, expliquerait pourquoi la seule ablation des deux reins chez l'animal augmente assez peu la demi-vie plasmatique du peptide natriurétique auriculaire [35]. Chez de tels animaux, l'administration de thiorphan retarde encore l'élimination du peptide natriurétique auriculaire exogène de la circulation, témoignant de l'importance de la NEP extrarénale dans ce catabolisme. Ainsi, le peptide natriurétique auriculaire et le BNP sont dégradés par les cellules endothéliales par l'intermédiaire de récepteurs de clairance et de la NEP.
Un autre substrat possible de la NEP endothéliale est la bradykinine qui est clivée, comme par l'ECA, en bradykinine 1-7 et 1-5. L'endothéline, enfin, peut être inactivée par la NEP par une série d'hydrolyses. Toutefois, le rôle physiologique de la NEP dans la dégradation de l'endothéline n'est pas clairement établi.

La NEP fait partie, comme l'ECA, de la super-famille des métalloprotéases à zinc et possède la séquence consensus du site actif. La similarité du mécanisme d'action catalytique favorise la conception et la synthèse d'inhibiteurs mixtes de la NEP et de l'ECA. Des inhibiteurs mixtes, avec un $\mathrm{Ki}$ équivalent pour les deux enzymes, de l'ordre de la nanomole, ont été récemment synthétisés [36] et d'autres sont en cours d'étude. Bloquant la conversion de l'angiotensine I en angiotensine II, inhibant la dégradation de la bradykinine et potentialisant la demi-vie du peptide natriurétique auriculaire, ils offrent un grand attrait théorique en pathologie cardiovasculaire car ils pourraient se révéler plus efficaces que les seuls inhibiteurs de l'ECA, comme l'indique l'effet de la coadministration d'un inhibitcur de l'enzyme de conversion et d'un inhibitcur de la NEP dans l'hypertension expérimentale [37].

A l'inverse de l'ECA, il n'existe pratiquement pas de NEP circulante dans le plasma : la NEP qui est inséréc dans la membrane plasmique par son extrémité $\mathrm{N}$-terminale ne subit pas de maturation protéolytique posttraductionnelle. Par ailleurs, il n'existe ni régulation physiopathologique connue de cette enzyme en pathologic cardiovasculaire, ni déterminisme génétique identifié pouvant influencer son niveau d'expression tissulaire.

\section{Enzyme de conversion de l'endo- théline (ECE)}

L'endothélium synthétise un peptide vasoconstricteur à action locale, l'endothéline, découverte par Yanasigawa et al. en 1988, dans des cultures de cellules endothéliales bovines (voir $\mathrm{m} / \mathrm{s} n^{\circ} 7$, vol. 4, p. 462 et [38]). Il existe trois isoformes des endothélines (ET1, ET2 et ET3) mais la cellule endothéliale ne synthétise que 

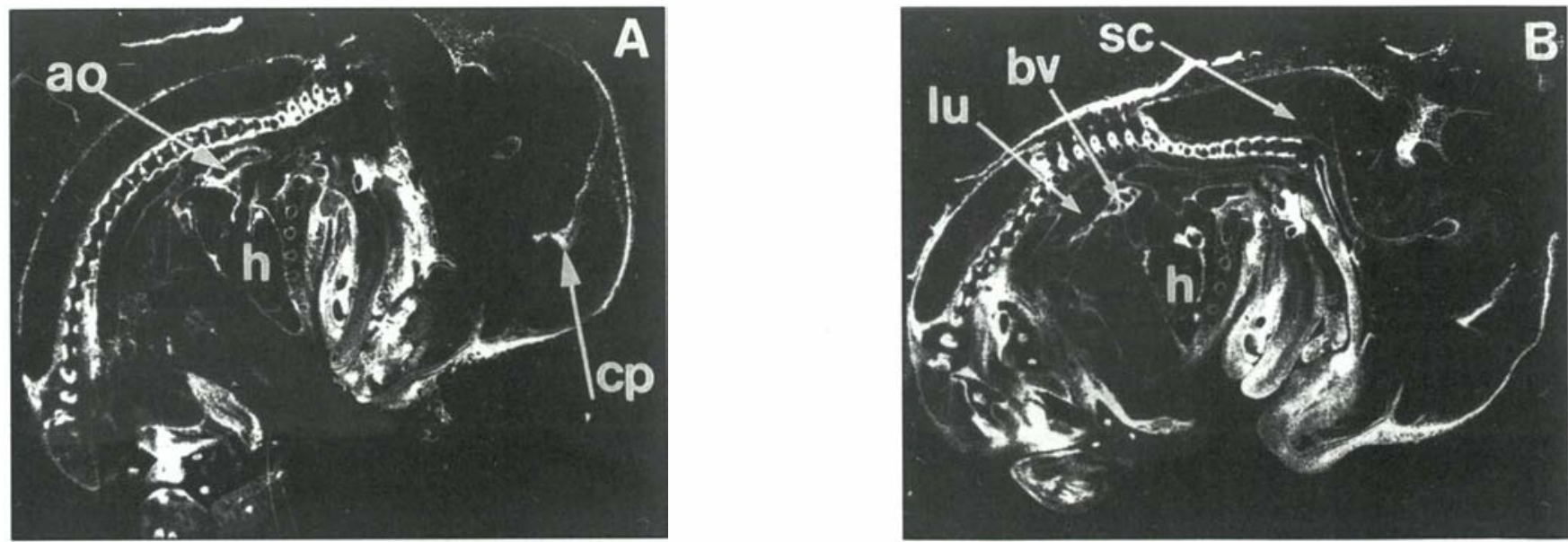

Figure 5. Autoradiographies montrant la localisation de l'endopeptidase neutre dans des structures vasculaires embryonnaires grâce à l'inhibiteur tritié [ ${ }^{3} H$ ]HACBO-Gly. Coupes sagittales d'embryons de rats à 16 jours (tête de l'embryon du côté droit) $(A)$ : ao = aorte, $h=$ cœur, $c p=$ plexus choroïdes. $(B): s c=$ moelle épinière, lu = poumon, bv = vaisseaux sanguins. (Clichés aimablement fournis par I. Dutriez et al. [33].)

l'endothéline 1. Les endothélines sont des peptides cycliques de 21 acides aminés, présentant deux ponts disulfures. Le gène, l'ADNc, la structure et la maturation des trois endothélines sont similaires. L'endothéline 1 est issue d'un précurseur de 203 acides aminés, la préproendothéline. La big endothéline, formée à partir de ce précurseur, est mûrie en endothéline par clivage au niveau d'une liaison tryptophane-valine. Ce clivage s'effectue par une enzyme appelée endothelin converting enzyme (ECE).

La big endothéline est pratiquement dénuée de l'activité vasoconstrictive et hypertensive de l'endothéline $(1 / 100$ e de l'activité pressive). La cellule endothéliale ne contenant pas de granules de stockage et de maturation de la big endothéline ou de l'endothéline 1 , la maturation s'effectue donc vraisemblablement lors du routage extracellulaire de la big endothéline, sans doute au niveau de la membrane basale de la cellule endothéliale. L'ECE semble être une métalloprotéase à zinc, inhibée par l'EDTA, présente dans les membranes plasmiques des cellules endothéliales [39]. Son activité est bloquée par le phosphoramidon, un inhibiteur des métalloprotéases à zinc, mais non par le thiorphan et le captopril, ce qui exclut la participation de l'ECA et de la NEP dans la conversion de la big endothéline en endothéline [40]. Des expériences in vitro et in vivo semblent $\mathrm{m} / \mathrm{s} n^{\circ} 10 \mathrm{vol} .9$, octobre 93 conforter cette hypothèse : l'administration de big endothéline par voie intraveineuse élève la pression artérielle de l'animal, élévation abolie par la coadministration de phosphoramidon [41] ; la production d'endothéline dans le milieu de culture des cellules endothéliales est fortement diminuée par la présence de phosphoramidon alors que la big endothéline est toujours sécrétée [42]. Une recherche active, tant biochimique que pharmacologique, a lieu actuellement sur cette enzyme car l'inhibition de la conversion de la big endothéline en endothéline permettrait de mieux cerner le rôle physiopathologique de l'endothéline et de conduire à des composés pharmacologiques potentiellement hypotenseurs et protecteurs vasculaires.

\section{Données récentes sur la synthèse, le transport ou la production locale de peptides vasoactifs dans la paroi vasculaire}

L'endothélium et la paroi vasculaire produisent des peptides vasoactifs par des voies variées : synthèse ou, plus vraisemblablement, production locale d'angiotensine II à partir des éléments du système rénine piégés au niveau de la paroi vasculaire; production locale de bradykinine, hypothèse nouvelle et attrayante ; synthèse d'endothéline. Tous ces peptides exercent une action sur le tonus vasculaire et, potentiellement, sur la prolifération des cellules musculaires lisses vasculaires.

\section{Angiotensine II}

A côté du système rénineangiotensine circulant, dont les éléments sont la rénine synthétisée et sécrétée par le rein et l'angiotensinogène produit par le foie, existent des arguments pour la présence d'une production locale d'angiotensine, dans la paroi vasculaire [43]. La présence de l'ARNm de l'angiotensinogène, de rénine et d'angiotensinogène a été montrée dans la paroi des vaisseaux. L'angiotensine II pourrait être produite dans le milieu de culture des cellules endothéliales bovines [44]. Toutefois, ces résultats doivent être analysés avec précaution: les quantités d'AR Nm d'angiotensinogène et les concentrations tissulaires de rénine et d'angiotensinogène sont extrêmement faibles. La rénine est synthétisée sous la forme d'un précurseur inactif, la prorénine, qui doit être converti en rénine. Or, jusqu'à présent, on a montré que seules les cellules juxtaglomérulaires rénales, et peut-être les cellules surrénaliennes, sont équipées pour effectuer cette maturation. Celle-ci n'a pas été démontrée dans les cellules endothéliales ou les autres cellules de la paroi 


\section{RÉFÉRENCES}

47. Powell JS, Clozel JP, Mueller RKM, Kuhn H, Hefti $H$, Hosang M, Baumgartner HR. Inhibitors of angiotensin converting enzyme prevent myointimal thickening after vascular injury. Science $1989 ; 245$ : 186-245.

48. Mineo $\mathrm{C}$, Yagyu $\mathrm{Y}$, Imanaka $\mathrm{T}$, Takano T. Transcellular transport of angiotensin II through a cultured arterial endothelial monolayer. Exp Cell Res $1990 ; 190$ : 99-103.

49. Campbell DJ. Circulating and tissue angiotensin systems. $J$ Clin Invest $1987 ; 79$ : $1-6$.

50. Danser AHS, Koning MMG, Admiraal PJS, Derkx FHM, Verdouw PD, Schalekamp MADH. Use of 125-Iodine labeled angiotensin I to study the metabolism of endogenous angiotensin I by different tissues in intact animal. Am J Physiol $1992 ; 263$ : H418-28.

51. Danser AHS, Koning MMG, Admiraal PJJ, Sassen LMA, Derkx FHM, Verdouw PP, Schalekamp MADH. Production of angiotensin I and II in the intact pig. $A m$ $J$ Physiol 1992 ; 263 : H429-37.

52. Schmaier AH, Kuo A, Lundberg D, Murray S, Lines DB. The expression of high molecular weight kininogen on human umbilical vein endothelial cells. Proc Natl Acad Sci USA 1988 ; 263 : 16327-33.

53. Oza NB, Schwartz JH, Goud DH, Levinski NG. Rat aortic smooth muscle cells in culture express kallikrein, kininogen and bradykininase activity. J Clin Invest 1992 ; 85 : 597-600.

54. Saed GM, Carretero OA, Scicli AG. Kallikrein messenger RNA in rat arteries and veins. Circ Res 1990; 67 : 510-6.

55. Keravis MT, Nehlig H, Delacroix MF, Regoli D, Hiley RR, Stoclet JC. High affinity bradykinin $\mathrm{B} 2$ binding sites sensitive to guanine nucleotides in bovine aortic endothelial cells. Eur J Pharmacol 1991; 207 : 149-55.

56. Mombouli JV, Vanhoutte P. Kinins and endothelium-dependent relaxations to converting enzyme inhibitors in perfused canine arteries. J Cardiovasc Pharmacol 1991 $18: 926-7$

57. Wiemer G, Scholkens BA, Becker RHA, Busse R. Ramiprilat enhances endothelial antacoid formation by inhibiting breakdown of endothelium-derived bradykinin. Hypertension $1991 ; 18$ : 558-63.

58. Masaki T. Endothelins : homeostatic and compensatory actions in the circulatory and endocrine systems. Endocrine Rev 1993 ; $14: 256-68$

59. Simonson MS, Dunn M-J. Cellular signaling by peptides of the endothelin gene family. FASEB J $1990 ; 4$ : 2989-3000.

60. Lee ME, Termizer DH, Clifford JA, Quertermous T. Cloning of the GATAbinding protein that regulates endothelin-1 gene expression in endothelial cells. $J$ Biol Chem 1991; 266 : 16188-92.

61. Rubanyi GM. Potential physiological and pathological significance of endothelins. Drugs Future 1992 ; 17 : 915-36. vasculaire. Enfin, il n'existe pas de colocalisation de la rénine et de l'angiotensinogène dans les cellules de la paroi vasculaire puisque la rénine se situerait principalement dans les cellules endothéliales et les cellules musculaires lisses et l'angiotensinogène dans les cellules de l'adventice.

L'angiotensine II exerce un effet vasoconstricteur puissant sur les cellules musculaires lisses vasculaires. A côté de cette action bien connue, l'angiotensine II pourrait, dans certaines conditions, avoir un effet trophique et mitogénique sur ces cellules. L'angiotensine II exerce une action mitogénique dans des cellules $\mathrm{CHO}$ transfectées exprimant en abondance le récepteur AT1 de l'angiotensine II, en l'absence de sérum de veau fotal [45]. Un effet similaire peut s'observer dans les cellules musculaires lisses vasculaires mais en présence seulement de facteurs de croissance, tels que ceux contenus dans le sérum de veau fotal [46]. L'angiotensine II pourrait contribuer à la prolifération des cellules musculaires lisses vascu-

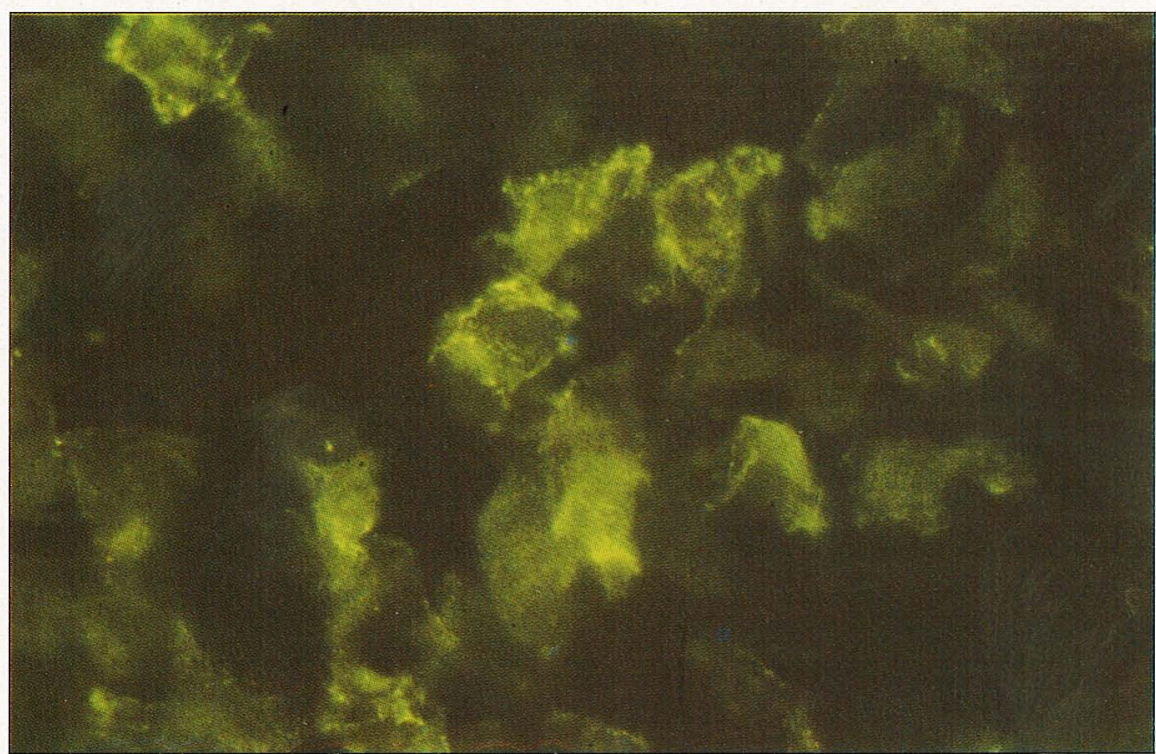

Figure 6. Immunofluorescence de l'endopeptidase neutre (NEP) à la surface des cellules endothéliales de lapin en culture. La présence de la NEP est révélée par la fluorescence verte à la membrane des cellules. Cette coloration apparaît à la fois de façon diffuse sur toute la membrane, et pointillée, révélant probablement des sites de forte concentration d'enzyme à la surface cellulaire. X500. (Cliché J.-M. Gasc, Inserm U. 36.) laires dans des circonstances patholoqui suit la dénudation de l'endothélium chez le rat [47].

Un grand nombre de questions restent sans réponse : comment l'angiotensine II engendrée dans le secteur plasmatique atteint-elle les cellules musculaires lisses vasculaires? L'angiotensine II pourrait circuler entre les cellules endothéliales dans les endothéliums fenestrés, mais doit passer à travers les cellules endothéliales dans les endothéliums à jonction serrée. Un transport actif transendothélial, spécifique et unidirectionnel de la surface apicale à la surface basolatérale, peut-être par l'intermédiaire de vésicules de transport, a été suggéré mais insuffisamment étudié [48]. Existe-t-il une diffusion passive des éléments circulants plasmatiques du système rénine-angiotensine dans la paroi vasculaire et quelle est leur importance dans la production locale d'angiotensine II [49] ? Des études élégantes menées chez l'animal giques, comme la sténose carotidienne et chez l'homme ont montré indirec- 
tement que les angiotensines I et II pouvaient être vraisemblablement produites localement dans la paroi vasculaire, à partir de la rénine et de l'angiotensinogène circulants séquestrés dans la paroi artérielle : l'équipe de M. Schalekamp a montré, par des expériences de clairance métabolique de l'angiotensine I et de l'angiotensine II radioactives, que ces peptides pouvaient être engendrés dans la paroi vasculaire à partir des éléments circulants du système rénine, vraisemblablement piégés localement [50, 51]. La formation tissulaire d'angiotensine I dans les lits vasculaires extrarénaux dépendrait essentiellement de la rénine d'origine rénale piégée localement $[50,51]$. L'importance relative de ce système local par rapport au système rénine circulant classique ne peut encore être évaluée à l'heure actuelle.

\section{Bradykinine}

La production de bradykinine par les vaisseaux est une hypothèse nouvelle et attrayante. En effet, la bradykinine n'est pas une hormone circulante. Le foie synthétise et secrète dans le plasma la prékallicréine qui est inactive du fait de sa structure de proenzyme et du complexe qu'elle forme avec le kininogène de haut poids moléculaire. L'activation de la pré-kallicréine en kallicréine se fait par protéolyse partielle lors de l'activation des systèmes de coagulation (facteur XII) et de fibrinolyse (plasmine). Les kinines alors produites augmentent la perméabilité capillaire localement. Les kallicréines tissulaires, synthétisées dans le rein, le pancréas, la sous-maxillaire, peuvent hydrolyser la bradykinine à partir de son substrat mais, lorsqu'elles sont secrétées dans le plasma, elles sont rapidement inactivées du fait de leur interaction avec les inhibiteurs circulants des sérines protéases.

Une question importante est donc de savoir si la bradykinine peut être synthétisée localement dans la paroi artérielle, notamment par les cellules endothéliales. La bradykinine provoque une vasorelaxation par la mise en jeu de deux grands médiateurs, la prostacycline et le monoxyde d'azote : l'interaction de la bradykinine avec son récepteur endothélial à $\mathrm{m} / \mathrm{s} n^{\circ} 10 \mathrm{vol}$. 9, oclobre 93 sept domaines transmembranaires couplé aux protéines $G$ entraîne une augmentation de calcium intracellulaire qui a pour double effet d'une part, d'activer la phospholipase A2 et de produire la prostacycline, et, d'autre part, de stimuler la NO synthase constitutive et d'engendrer du monoxyde d'azote (NO). Prostacycline et $\mathrm{NO}$ agissent de concert sur la cellule musculaire lisse vasculaire sous-jacente pour produire une vasorelaxation.

Plusieurs arguments, à vrai dire encore préliminaires, plaident en faveur d'une production locale de bradykinine dans la paroi vasculaire. Les cultures de cellules endothéliales ombilicales humaines synthétisent et sécrètent du kininogène de haut poids moléculaire [52]. Elles sont capables de fixer et d'internaliser les kinines exogènes. Par ailleurs, les cellules musculaires lisses vasculaires d'aorte de rat en culture produisent de la kallicréine et du kininogène [53, 54]. La bradykinine engendrée aurait un effet paracrine sur les récepteurs B2 des cellules endothéliales [55]. Un autre argument, indirect, provient des expériences pharmacologiques in vitro. L'administration d'inhibiteur de l'enzyme de conversion sur des anneaux aortiques ayant subi une constriction préalable entraîne une vasorelaxation, en présence d'endothélium. Celle-ci peut être bloquée par un antagoniste spécifique de la bradykinine, impliquant la mise en jeu de ce peptide dans la vasorelaxation [56]. La suppression de l'endothélium dans cette préparation entraîne la perte de la relaxation induite par l'inhibiteur de l'enzyme de conversion. De même, le traitement des cellules endothéliales en culture par un inhibiteur de l'enzyme de conversion provoque des modifications $\mathrm{du} \mathrm{Ca}^{2+}$ intracellulaire et une production de prostaglandines qui peuvent être inhibées par un antagoniste compétitif des kinines [57]. A long terme, la bradykinine pourrait avoir une action antiproliférative sur la paroi vasculaire par la mise en jeu de médiateurs endothéliaux, comme le NO, qui diminuent la mitogenèse des cellules musculaires lisses vasculaires.

Ainsi serait-on en présence d'une situation complexe : production locale de bradykinine dans la paroi vasculaire ; effet auto- ou paracrine de la bradykinine via les médiateurs de la cellule endothéliale agissant sur les cellules musculaires lisses vasculaires ; arrêt de l'action par inactivation de la bradykinine grâce à l'ECA et la NEP endothéliales.

\section{Endothéline}

L'endothéline 1 produite par les cellules endothéliales est un autre exemple de synthèse d'un peptide vasoactif par la cellule endothéliale avec effet paracrine et peut-être autocrine. L'endothéline 1 exerce tout d'abord un effet vasodilatateur bref, dont l'importance varie en fonction du territoire vasculaire étudié. Cette action est suivie d'un eff et vasoconstricteur et hypertenseur très puissant et prolongé [58]. En outre, l'endothéline exerce un effet mitogénique sur les cellules musculaires lisses vasculaires et les cellules mésangiales glomérulaires rénales [59].

L'endothéline 1 agit sur un récepteur couplé aux protéines $\mathrm{G}$ (récepteur $\mathrm{ET}_{\mathrm{A}}$ ) localisé dans les cellules musculaires lisses vasculaires. La stimulation de ce récepteur entraîne une activation de la phospholipase $\mathrm{C}$, une augmentation du calcium intracellulaire et une vasoconstriction. Il existe un deuxième type de récepteur de l'endothéline, $\mathrm{ET}_{\mathrm{B}}$, situé au niveau des cellules endothéliales. Dans les conditions normales, le taux de ce récepteur serait contrôlé de façon négative par la production d'endothéline 1 des cellules endothéliales. La stimulation de ce récepteur endothélial par l'endothéline pourrait expliquer l'action vasorelaxante initiale de l'endothéline observée in vitro. En effet, sa stimulation entraîne, via la mobilisation de calcium intracellulaire, une augmentation de prostacycline et une activation de la NO synthase avec production de monoxyde d'azote à effet vasodilatateur, par le même mécanisme que celui mis en jeu par la bradykinine. L'endothéline 1 est donc un médiateur à effet paracrine et en partie autocrine. La dualité d'action de l'endothéline 1 - vasorelaxante (et hypotensive) puis vasocontracturante (et hypertensive) - montre bien que le même médiateur peut avoir un effet opposé suivant qu'il exerce son 
action sur la cellule endothéliale ou sur la cellule musculaire lisse vasculaire. L'importance relative de la vasorelaxation ou de la vasoconstriction dans différents territoires vasculaires dépend de plusieurs phénomènes, dont la balance locale entre la production d'endothéline et celle du monoxyde d'azote.

La régulation de la production d'endothéline est essentiellement transcriptionnelle et a fait l'objet d'études détaillées [60]. De nombreux facteurs comme l'hypoxie, les forces de cisaillement, des hormones comme l'angiotensine II ou la vasopressine, stimulent la transcription du gène de l'endothéline 1. L'endothéline circule dans le plasma à faible concentration (pmol/l). Les variations de l'endothéline plasmatique en pathologie vasculaire sont de faible amplitude, mais l'endothéline circulante pourrait n'être qu'un reflet indirect et infidèle des variations tissulaires. On a, en effet, émis l'hypothèse que la production d'endothéline pourrait se faire principalement du côté basal de la cellule endothéliale.

L'importance en physiologie et en pathologie cardiovasculaires de l'endothéline reste encore très hypothétique. Des antagonistes des récepteurs des endothélines ont été découverts récemment : il s'agit de peptides cycliques et linéaires ou de produits naturels non peptidiques. Ces antagonistes inhibent de façon plus spécifique le récepteur $\mathrm{ET}_{\mathrm{A}}$ que le récepteur $\mathrm{ET}_{\mathrm{B}}[61]$. Compte tenu des effets pathologiques supposés de l'endothéline, ils pourraient avoir un effet antihypertenseur chez le rat génétiquement hypertendu, diminuer l'hypertrophie cardiaque secondaire à l'hypertension, lever le vasospasme après hémorragie méningée, diminuer l'hypertension artérielle pulmonaire. En résumé, l'endothélium vasculaire est un site important de production et de métabolisme des peptides vasoactifs. Ces peptides ont un effet autocrine et (ou) paracrine sur les cellules musculaires lisses vasculaires dont ils contrôlent la tonicité et influencent la croissance. Pour ces raisons, l'endothélium est une cible pharmacologique privilégiée pour la recherche d'inhibiteurs des ectopeptidases et d'antagonistes compétitifs des peptides vasoactifs

\section{Summary}

The vascular endothelium, a site of production and metabolism of vasoactive peptides

The vascular endothelium possesses many properties, including production and metabolism of vasoactive peptides. This is a key function for the control of the vascular tone and of the structure of the arterial wall. Three ectoenzymes, belonging to the zinc metallo-peptidases family, are involved : angiotensin I converting enzyme (ACE) that activates angiotensin I into angiotensin II and that degrades bradykinin; neutral endopeptidase (NEP) that inactivates bradykinin and atrial natriuretic peptide ; endothelin converting enzyme (ECE), that generates endothelin from its inactive precursor, big endothelin. The vascular wall is also probably able to uptake and concentrate some elements of circulating reninangiotensin system. Endothelial cells synthetize bradykinin and endothelin I that exert a paracrine effect on vascular smooth muscle cells. Therefore, endothelial cells control the production of vasoactive peptides and thereby the local tissular blood flow and the growth of vascular smooth muscle cells. Because of its location between blood and vascular tissues, endothelium is a good target for drugs interfering with the synthesis and (or) the action of vasoactive peptides.

\section{TIRÉS A PART}

P. Corvol. 